\title{
Confirmação da ocorrência de Abolboda poarchon Seub. (Xyridaceae) no Estado de São Paulo, Brasil
}

\author{
Alessandra Ike Coan ${ }^{1,3}$, Aline Oriani² e Julio Antonio Lombardi ${ }^{2}$
}

Recebido em 3/10/2008. Aceito em 12/03/2009

RESUMO - (Confirmação da ocorrência de Abolboda poarchon Seub. (Xyridaceae) no Estado de São Paulo, Brasil). A ocorrência de Abolboda poarchon Seub. é documentada para o Estado de São Paulo, com base em coletas realizadas no município de Itirapina. O trabalho apresenta a descrição detalhada de A. poarchon e A. pulchella, espécies simpátricas, com características diagnósticas e distintivas para o reconhecimento das mesmas no campo.

Palavras-chave: campo úmido, flora, monocotiledôneas, neotrópicos, Poales

ABSTRACT - (Confirmation of occurrence of Abolboda poarchon Seub. (Xyridaceae) in São Paulo State, Brazil). The occurrence of Abolboda poarchon in São Paulo State is documented, based on collections from Itirapina municipality. This paper presents a detailed description of the sympatric species, A. poarchon and A. pulchella, emphasizing some diagnostic features for field identification.

Key words: flora, herbaceous swamp, monocotyledons, neotropics, Poales

\section{Introdução}

Xyridaceae apresenta distribuição pantropical e inclui cerca de 385 espécies agrupadas em cinco gêneros: Abolboda Humb. \& Bonpl., Achlyphila Maguire \& Wurdack, Aratitiyopea Steyerm. \& P. Berry, Orectanthe Maguire e Xyris L. (Kral 1998). Para Abolboda são reconhecidas 23 espécies restritas à América do Sul (Campbell 2005), com centro de diversidade no norte da bacia do Rio Amazonas, das Guianas até o sudeste da Colômbia (Smith \& Downs 1968).

No Brasil ocorrem seis espécies de Abolboda, sendo que para o Estado de São Paulo havia confirmação de apenas uma, Abolboda pulchella Humb. \& Bonpl., referida também para o Pará, Acre e Mato Grosso, onde cresce em locais brejosos e pantanosos, com solo arenoso ou rico em matéria orgânica (Wanderley et al. 2003).

A ocorrência de Abolboda poarchon Seub. no Estado de São Paulo foi inicialmente referida por Smith \& Downs (1968), baseados em um único registro, depositado no Muséum National d'Histoire Naturelle (P) (A. St.-Hilaire 1281). Wanderley et al. (2003), no entanto, no levantamento das Xyridaceae do Estado de São Paulo, não encontraram materiais desta espécie nas coleções dos herbários brasileiros visitados.

Abolboda poarchon é restrita ao Brasil e ocorre em campos arenosos ou rochosos úmidos e bordas de florestas de galeria, de 400 a 1.300 metros de altitude, muitas vezes em simpatria com A. pulchella (Kral 1992), tendo sido referida para o Amazonas, Pará, Mato Grosso e Minas Gerais (Kral 1992), com floração em setembro (Seubert 1855; Smith \& Downs 1968).

No presente trabalho, por meio de coletas recentes realizadas pelos autores no município de Itirapina, é comprovada a ocorrência de Abolboda poarchon no Estado de São Paulo. Além disso, características diagnósticas para o reconhecimento da espécie no campo são fornecidas, em comparação com A. pulchella.

\section{Material e métodos}

Os exemplares analisados são provenientes do município de Itirapina, Estado de São Paulo, Brasil, e foram acompanhados no campo semanalmente entre setembro a novembro/2007. A área de ocorrência corresponde a um campo de pastagem, com solo arenoso, parcialmente encharcado. O material testemunho está depositado no Herbário Rioclarense (HRCB), da Universidade Estadual Paulista Câmpus de Rio Claro, São Paulo.

A identificação de Abolboda poarchon Seub. foi baseada nas chaves de identificação de Smith \& Downs (1968) e de Kral (1992). Os resultados foram documentados por meio de fotografias feitas no campo e sob estereomicroscópio com câmera fotográfica acoplada. São fornecidas descrições detalhadas de A. poarchon e de A. pulchella Humb. \& Bonpl., bem como características que distinguem essas duas espécies no campo.

\section{Resultados e discussão}

A partir de documentação obtida em campo, confirma-se a ocorrência natural de Abolboda poarchon no Estado de São Paulo, Brasil.

Abolboda poarchon Seub., Fl. bras. 3: 223, t. 30. 1855.

Erva anual, cespitosa, ca. $23 \mathrm{~cm}$ alt. Raízes delicadas e esponjosas. Caule rizomatoso, delgado, ca. 2,3 mm diâm. Folhas rosuladas, 3,0-7,5×0,2-0,5 cm; bainha curta, pouco mais larga que a lâmina; lâmina levemente curva, ápice obtuso, apiculado, margem lisa e glabra. Escapo cilíndrico, ca. $21 \mathrm{~cm}$ compr., verde, envolvido na base por 3 brácteas de diferentes comprimentos; brácteas do escapo 2 , subopostas, externa ca. $2,6 \mathrm{~cm}$ compr. e interna ca. $2,3 \mathrm{~cm}$ compr., lanceoladas, apiculadas, inseridas ca. $12 \mathrm{~cm}$ da base

1 Universidade Federal do Paraná, Departamento de Botânica, Setor de Ciências Biológicas, Curitiba, PR, Brasil

2 Universidade Estadual Paulista, Instituto de Biociências, Departamento de Botânica, Rio Claro, SP, Brasil

3 Autor para correspondência: alessandra.coan@ufpr.br 
do escapo. Inflorescência em espiga, pauciflora (4-8 flores), 1,1-1,7×0,7-1,0 cm; brácteas florais divergentes, imbricadas, ovais, ápice agudo, espessadas na região mediana, ca. $1 \mathrm{~cm}$ compr. Flores com 2 sépalas laterais livres, lanceoladas, ca. $1,25 \mathrm{~cm}$ compr.; pétalas com lobos desenvolvidos, roxoazuladas; estames 3, anteras dorsifixas, sagitadas, extrorsas, ca. $4 \mathrm{~mm}$ compr., amarelas; estaminódios 3, filiformes, ca. $1,15 \mathrm{~cm}$ compr.; ovário trilocular, obovóide, ca. $3 \mathrm{~mm}$ compr., verde, ápice 3-lobado com tricomas; estilete ca. 1,4 cm compr., tripartido na porção apical, portando 3 apêndices a ca. de
$4 \mathrm{~mm}$ da base, os laterais claviformes, reflexos, ca. $2 \mathrm{~mm}$ compr., com porção superior arredondada, o mediano rudimentar, filamentoso e reflexo; estigmas fimbriados, roxos. Fruto cápsula loculicida. Sementes elipsóides, estriadas longitudinalmente, marrons.

Material examinado: BRASIL. São Paulo: Itirapina, Rodovia Washington Luís, km 107, Coan \& Oriani 61, 24/X/2007 (HRCB); ibidem, Coan \& Oriani 72, 5/XI/2007 (HRCB).

Fenologia: floresce de outubro a novembro e frutifica de novembro a dezembro.
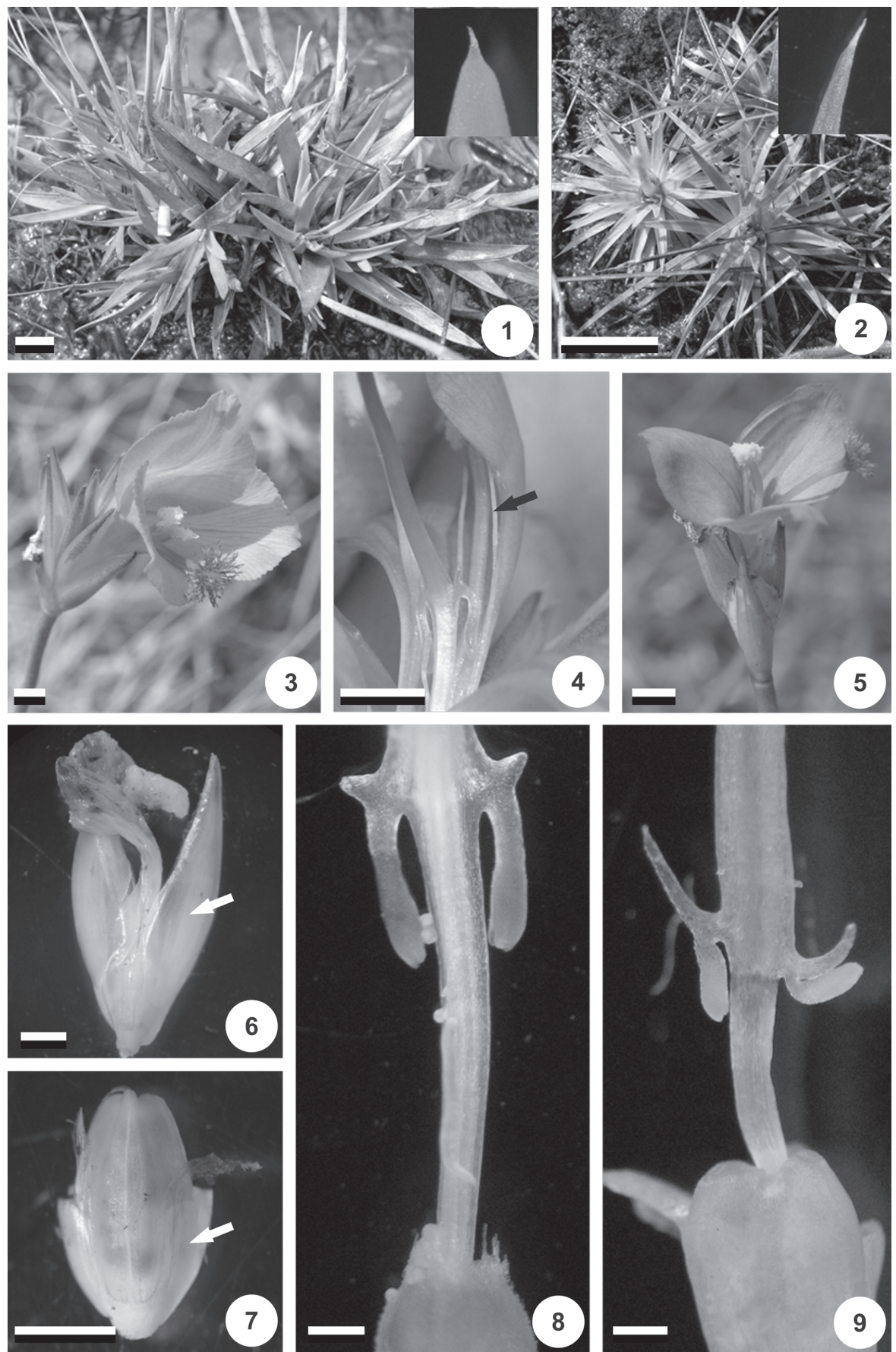

Figuras 1-9. Aspectos morfológicos comparativos entre Abolboda poarchon Seub. (1, 3-4, 6, 8) e A. pulchella Humb. \& Bonpl. (2, 5, 7, 9) em populações simpátricas no município de Itirapina, São Paulo, Brasil. 1-2. Rosetas, com detalhe dos ápices foliares. 3 e 5. Inflorescências com flor em antese. 4. Detalhe dos estaminódios (seta). 6-7. Sépalas (seta). 8-9. Detalhe da porção apical do ovário e apêndices laterais do estilete. Barras = 1-2: 1 mm; 3-7: 2 mm; 8-9: 0,5 mm. 
Abolboda pulchella Humb. \& Bonpl., Pl. aequinoct. 2: 110. 1813.

Erva anual, cespitosa, ca. $18 \mathrm{~cm}$ alt. Raízes delicadas e esponjosas. Caule rizomatoso, delgado, ca. 2,5 mm diâm. Folhas rosuladas, 1,8-5,0×0,1-0,2 cm; bainha curta, pouco mais larga que a lâmina; ápice agudo, apiculado, margem lisa e glabra. Escapo cilíndrico, ca. $15 \mathrm{~cm}$ compr., verde, envolvido na base por 3 brácteas de diferentes comprimentos; brácteas do escapo 2, subopostas, externa ca. 2,2 cm compr. e interna ca. $1,8 \mathrm{~cm}$ compr., lanceoladas, apiculadas, inseridas ca. $10 \mathrm{~cm}$ da base do escapo. Inflorescência em espiga, pauciflora (7-11 flores), 1,2-1,8× 0,5-0,7 cm; brácteas florais divergentes, imbricadas, ovais, ápice agudo, espessadas na região mediana, ca. $1 \mathrm{~cm}$ compr. Flores com 2 sépalas laterais livres, campanuladas, ca. $0,3 \mathrm{~cm}$ compr.; pétalas com lobos desenvolvidos, roxo-azuladas; estames 3, anteras dorsifixas, sagitadas, extrorsas, ca. 3,5 mm compr., amarelas; ovário trilocular, obovóide, ca. $3,4 \mathrm{~mm}$ compr., verde, ápice 3-lobado glabro; estilete ca. $0,8 \mathrm{~cm}$ compr., tripartido na porção apical, portando 3 apêndices a ca. de 2,8 mm da base, os laterais espatulados, reflexos, com a porção superior desenvolvida e corniforme, 1,8-3,2 mm compr., o mediano rudimentar, filamentoso e reflexo; estigmas fimbriados, roxos. Fruto cápsula loculicida. Sementes elipsóides, estriadas longitudinalmente, marrons.

Material examinado: BRASIL. São Paulo: Itirapina, Rodovia Washington Luís, km 107, Scatena et al. 270, 10/XI/2005 (HRCB); ibidem, Scatena et al. 299, 25/XI/2006 (HRCB); ibidem, Coan \& Oriani 60, 24/X/2007 (HRCB); ibidem, Coan \& Oriani 71, 5/XI/2007 (HRCB).

Fenologia: floresce de outubro a novembro e frutifica de novembro a dezembro.

Abolboda poarchon ocorre em simpatria com A. pulchella, compartilhando também o período de floração e, provavelmente, a guilda de visitantes e polinizadores. Embora ambas as espécies apresentem grande similaridade morfológica, a análise minuciosa revela que elas diferem entre si pela morfologia das folhas e das sépalas, pela presença ou ausência de estaminódios, forma e inserção dos apêndices no estilete e pela superfície do ápice do ovário (Fig. 1-9).

Em Abolboda poarchon, as folhas são lanceoladas, com ápice obtuso e apiculado (Fig. 1 - detalhe); as sépalas são lanceoladas (Fig. 6 - seta), maiores que a bráctea floral, e os estaminódios são desenvolvidos, filiformes (Fig. 4 - seta). Os apêndices do estilete são claviformes, com a porção superior arredondada e inconspícua, e ocorrem tricomas na porção apical do ovário (Fig. 8).

Em Abolboda pulchella, as folhas são mais estreitas e apresentam ápice agudo, apiculado (Fig. 2 - detalhe). As sépalas são campanuladas (Fig. 7 - seta), totalmente envolvidas pela bráctea floral e mais curtas do que esta, e os estaminódios não são evidentes. Os apêndices do estilete são espatulados, com a porção superior desenvolvida e corniforme, inserindo-se mais próximos do ovário, e este apresenta porção apical glabra (Fig. 9).

De acordo com Kral (1992) são reconhecidas duas variedades de Abolboda poarchon, var. intermedia e var. poarchon, distintas principalmente pelo tamanho das folhas e pelo período de abertura das flores. Segundo o autor, em A. poarchon var. intermedia a abertura das flores se dá no período matutino e as maiores folhas são menores que $10 \mathrm{~cm}$ de comprimento, enquanto que em $A$. poarchon var. poarchon a abertura se dá no período vespertino e as maiores folhas têm comprimento superior a $10 \mathrm{~cm}$. Analisando-se as descrições das duas variedades, conclui-se que os exemplares examinados no presente trabalho correspondem à variedade intermedia. Conforme observações no campo, a abertura das flores de A. poarchon ocorre no período matutino, entre $9 \mathrm{~h} 00$ e $11 \mathrm{~h} 00$, assim como verificado para os exemplares de populações simpátricas de A. pulchella.

A distribuição simpátrica de Abolboda poarchon e A. pulchella não se restringe à área de estudo, tendo sido verificada também por Kral (1992) a partir do levantamento de diversos materiais coletados no território brasileiro. Essa simpatria, aliada à similaridade morfológica e à sobreposição do período de floração, pode levar a erros de identificação no campo, o que ressalta a necessidade da reavaliação dos materiais coletados no Estado.

\section{Agradecimentos}

Os autores agradecem ao Instituto de Biociências, Universidade Estadual Paulista - UNESP, pelo suporte logístico para a realização das expedições semanais para documentação e coleta do material. Agradecem também aos assessores, pelos comentários e sugestões.

\section{Referências bibliográficas}

Campbell, L.M. 2005. Contributions towards a monograph of Xyridaceae: a revised nomenclature of Abolboda. Harvard Papers in Botany 10: 137-145.

Kral, R. 1992. A treatment of American Xyridaceae exclusive of Xyris. Annals of the Missouri Botanical Garden 79: 819-885.

Kral, R. 1998. Xyridaceae. Pp. 461-469. In: K. Kubitzki (ed.). The families and genera of vascular plants. IV. Flowering plants. Monocotyledons: Alismatanae and Commelinanae (except Gramineae). Berlin, Springer.

Seubert, M. 1855. Xyrideae. Pp. 209-224, tab. 22-30. In: C.F.P. Martius \& A.G. Eichler (eds.). Flora Brasiliensis, v.3, pars 1. Lipsiae, F. Fleischer.

Smith, L.B. \& Downs, R.J. 1968. Xyridaceae. Pp. 1-215, tab. 1-42. In: A.R. Teixeira (ed.). Flora Brasilica, v.9, fac. 12. São Paulo, Instituto de Botânica.

Wanderley, M.G.L.; Silva, M.B.C. \& Cerati, T.M. 2003. Xyridaceae. Pp. 333-348. In: M.G.L. Wanderley; G.J. Shepherd; A.M. Giulietti \& T.S. Melhem (eds.). Flora Fanerogâmica do Estado de São Paulo, v.3. São Paulo, Rima. 